\title{
Photocontrolled Release and Uptake of a Porphyrin Guest by Dithienylethene-Tethered $\beta$-Cyclodextrin Host Dimers
}

\author{
Alart Mulder, ${ }^{[a]}$ Amela Juković, ${ }^{[a]}$ Fijs W. B. van Leeuwen, ${ }^{[a]}$ Huub Kooijman, ${ }^{[b]}$ \\ Anthony L. Spek, ${ }^{[b]}$ Jurriaan Huskens, ${ }^{*[a]}$ and David. N. Reinhoudt ${ }^{*[a]}$
}

\begin{abstract}
Two photoswitchable dithienylethene-tethered $\beta$-cyclodextrin dimers were synthesized to function as host molecules with an externally controllable binding affinity. The cyclodextrin cavities of these dimers are linked through their secondary sides by a photochromic dithienylethene unit that is connected to the secondary rim either directly (4) or through propyl spacers (9). Irradiation with light switches these dimers between a relatively flexible (open) and a rigid (closed) form. The binding properties of the dimers depend on the configuration of the dithienylethene spacer, as is shown by microcalorimetry performed with tetra-
\end{abstract}

kis-sulfonatophenyl porphyrin (TSPP) as a guest molecule. The differences in binding properties are most pronounced for the more rigid dimer $\mathbf{4}$, which binds TSPP 35 times more strongly in the open form (4a) than in the closed form $(\mathbf{4 b})$. The values found for the enthalpy of binding $\left(\Delta H^{\circ}\right)$ indicate that this difference in binding is due to the loss of cooperativity between the two $\beta$-cyclodextrin cavities

Keywords: cooperative

phenomena $\cdot$ cyclodextrins $\cdot$ molecular recognition - photochromism • porphyrinoids in the closed form. Molecular modeling shows that $\mathbf{4 b}$ is not able to bind TSPP effectively in both cyclodextrin cavities. The open and closed forms of the more flexible dimer 9 show no substantial difference in their binding of TSPP. Thermodynamic values indicative of strong binding of TSPP by two $\beta$-cyclodextrin cavities were measured for both forms of the dimer, and molecular modeling confirms that both are flexible enough to tightly bind TSPP. The binding differences between the forms of dimer $\mathbf{4}$ allow the photocontrolled release and uptake of TSPP, which renders control of the ratio of complexed to free TSPP in solution possible.

\section{Introduction}

One of the ultimate challenges in chemistry is to obtain external control over molecular properties. This is especially true for the field of synthetic receptor molecules. ${ }^{[1]}$ External control over the selectivity of receptors gives access to tunable host molecules and ideally enables the release and/or uptake of guest molecules to be induced at will. Clear exam-

[a] A. Mulder, A. Juković, F. W. B. van Leeuwen, Dr. J. Huskens, Prof. Dr. D. N. Reinhoudt

Laboratory of Supramolecular Chemistry and Technology

MESA + Research Institute, University of Twente

PO Box 217, 7500 AE Enschede (The Netherlands)

Fax: (+31)53-4894645

E-mail: smct@ct.utwente.nl

[b] Dr. H. Kooijman, Prof. Dr. A. L. Spek

Bijvoet Center for Biomolecular Research

Crystal and Structural Chemistry, Utrecht University

Padualaan 8, $3584 \mathrm{CH}$ Utrecht (The Netherlands)

E-mail: a.L.spek@chem.uu.nl

$\left.{ }^{+}\right]$Correspondence concerning crystallography should be addressed to Prof. Dr. A. L. Spek. ples can be found among reported work on switchable cation receptors, which has led to tunable receptor molecules that enable the controlled release and transport of cations. ${ }^{[2]}$ In anlalogy to this work on cation receptors, Ueno et al. modified cyclodextrins with photoswitchable azobenzene moieties to obtain photocontrollable receptor molecules for small hydrophobic guests. ${ }^{[3]}$ Cyclodextrins are of special interest because of their ability to complex hydrophobic substrates in aqueous solutions, which leads to their application in a wide variety of fields such as pharmaceuticals, artificial enzymes, and biomimetic materials. ${ }^{[4]}$ A variety of photoswitchable cyclodextrins have been synthesized, but only marginal differences in binding affinity have been observed $^{[3 b-e]}$ for the different configurations of the photoswitchable unit, except in an early study by Ueno. ${ }^{[3 a]}$ More recently, considerable interest in cyclodextrin dimers tethered by tunable linkers has arisen. ${ }^{[5-8]}$ Cyclodextrin dimers are able to bind a large variety of guest molecules with relatively high binding constants compared to those of the parent cyclodextrins.

Ueno et al. were the first to report a tunable cyclodextrin dimer. $^{[5]}$ By tethering two $\beta$-cyclodextrin cavities with an azobenzene linker, they produced a photoswitchable $\beta$-cy- 
clodextrin dimer. However, no guest species were found that displayed selectivity for one of the two configurations of the dimer.

The groups of $\mathrm{Wu}^{[6]}$ and $\mathrm{Liu}^{[7]}$ have synthesized $\beta$-cyclodextrin dimers containing oligo(ethylenediamine) tethers. Upon coordination of metal ions, the tether flexibility of these dimers is altered, which results in a change in binding affinity. However, the dimers display only marginal differences in binding properties towards the guest molecules studied thus far.

Breslow et al. presented a nice example of a cyclodextrin dimer able to release guest molecules. Two $\beta$-cyclodextrin cavities were tethered through a photocleavable linker ${ }^{[8]} \mathrm{Ir}$ radiation of a dimer-guest complex led to the cleavage of the linker and the precipitation of the guest molecule. However, these dimers were destroyed irreversibly upon photoirradiation.

The use of a photoswitchable tether between the two cyclodextrin cavities is probably the most elegant choice for production of a tunable cyclodextrin dimer: photons are used to induce a switch between the two forms of the dimer without the need for additives to initiate switching, and with the proper choice of tether the photochromic switching process is fully reversible.

Among the photochromic molecules suitable for implementation in a photoswitchable receptor, dithienylethenes are the most promising. Dithienylethenes are photoswitchable molecules that are able to undergo thermally irreversible, fatigue-resistant, photochromic cyclization reactions that interconvert the molecule between two defined states: a relatively flexible open form and a rigid closed form. ${ }^{[9,10]}$ Dithienylethenes have been successfully exploited in the synthesis of photoswitchable saccharide ${ }^{[11]}$ and alkali metal ion receptors. ${ }^{[12]}$ In the open form, the two thiophene rings are capable of folding into a parallel conformation, which allows (possibly cooperative) interaction between the two thiophene-appended moieties. In the closed form, these moieties are spaced apart from each other in a rigid conformation. ${ }^{[11-13]}$ On the basis of this work, we reasoned that dithienylethenes could be used to photochemically tune the relative positions of two cyclodextrin cavities within a cyclodextrin dimer and thus could enable us to reversibly switch the molecule between mono- and ditopic binding and thereby achieve substantial differences in binding affinity.

Herein we report our findings on $\beta$-cyclodextrin dimers tethered by a dithienylethene linker. ${ }^{[14]}$ We have prepared two dithienylethene-tethered $\beta$-cyclodextrin dimers (4 and 9) with different connectivities between the cyclodextrins and the photochromic units (Scheme 1). In dimer 4, the dithienylethene moiety is attached directly at the secondary sides of the $\beta$-cyclodextrin cavities, which leads to a relatively rigid dimer with most of its rotational freedom in the dithienylethene spacer. Any change in the flexibility of the photochromic spacer may therefore lead to a change in conformational freedom of the dimer. As an alternative, the more flexible dimer 9 was synthesized, with the dithienylethene unit and the secondary sides of the $\beta$-cyclodextrin cavities separated by propyl spacers. The binding behavior of the dimers was studied by isothermal titration microcalorim- etry and UV/Vis spectroscopy. Molecular modeling was used as a supportive tool to help explain the differences in binding affinities.

\section{Results and Discussion}

Synthesis and characterization of the $\beta$-cyclodextrin dimers: The synthesis of the $\beta$-cyclodextrin dimers is outlined in Scheme 1. Dimer 4, in which the dithienylethene moiety is connected directly to the secondary rim of the cyclodextrin cavity, was synthesized from $\beta$-cyclodextrin amine $\mathbf{1}$ and 5,5'-(dicarboxydithienyl)cyclopentene ${ }^{[15]} \quad$ (2). 3-amino-3deoxy-heptakis(6-O-tert-butyldimethylsilyl)- $\beta$-cyclodextrin ${ }^{[16]}$ (1) was used as a precursor for dimer 4 to ensure selective and rigid coupling of the dithienylethene unit directly onto the secondary side of the $\beta$-cyclodextrin. Amide coupling of $\mathbf{1}$ and $\mathbf{2}$ with HBTU as a coupling agent gave the tert-butyldimethylsilyl (TBDMS)-protected dimer 3 in $65 \%$ yield. Subsequent deprotection of the primary hydroxy groups by treatment with trifluoroacetic acid gave the water-soluble dimer $\mathbf{4}$ in near-quantitative yield.

The modified sugar unit of the $\beta$-cyclodextrin amine $\mathbf{1}$ is altrosidic, whereas the remaining sugar units are glucosidic, which gives rise to a somewhat distorted $\beta$-cyclodextrin cavity. ${ }^{[17]}$ The altrose unit in dimer $\mathbf{4}$ adopts a ${ }^{4} \mathrm{C}_{1}$ conformation in aqueous solution, as shown by the measurement of its coupling constant $\left({ }^{3} J_{12}=4.1 \mathrm{~Hz}\right)$ in the ${ }^{1} \mathrm{H}$ NMR spectrum of 4. This value sharply contrasts the ${ }^{3} J$ coupling constant, ${ }^{3} J_{12}=7.3 \mathrm{~Hz}$, found for the altrose unit in dimer $\mathbf{3}$, which is indicative of an axial-axial coupling and implies that the altrose unit is in the more stable ${ }^{1} \mathrm{C}_{4}$ conformation. In aqueous solution, the conformational free energies of the ${ }^{4} \mathrm{C}_{1}$ and ${ }^{1} \mathrm{C}_{4}$ conformations of $\alpha$-D-altrose are nearly identical. ${ }^{[18]}$ It appears that hydrophobic interactions between the dithienylethene unit and the $\beta$-cyclodextrin cavity force the conformational equilibrium of the altrose unit towards the ${ }^{4} \mathrm{C}_{1}$ conformation, in which the dithienylethene spacer is directed towards the cavity. Similar results have been reported by Nolte et al. ${ }^{[19]}$ for $\beta$-cyclodextrin dimers with a flexible hydrophobic alkyl spacer as a linker. In aqueous solution, these dimers form self-inclusion complexes, with the hydrophobic alkyl tether included in one of the $\beta$-cyclodextrin cavities. However, there is no evidence for the formation of a self-inclusion complex of our dimer 4 . It is most likely that the dithienylethene spacer is positioned partly over the cavity rather than buried inside the cavity. The close proximity of the chiral cyclodextrin cavities is probably also responsible for the observed nonequivalence of the two diastereotopic protons of the cyclopentene bridge in the dithienylethene linker.

Dimer 9 was synthesized from 2 and mono-(2-O-(3-aminopropyl)-2-deoxy-heptakis(6-O-tert-butyldimethyl-silyl)- $\beta$ cyclodextrin (7) by a method analogous to that used for dimer 4 . The $\beta$-cyclodextrin propylamine 7 was synthesized by selective deprotonation of the more acidic $\mathrm{C} 2-\mathrm{OH}$ group of $\beta$-cyclodextrin derivative 5. ${ }^{[2]}$ Treatment of 5 with $\mathrm{LiH}$ and reaction with 1.1 equivalent commercially available 3 bromopropylphthalimide gave a statistical mixture of un- 

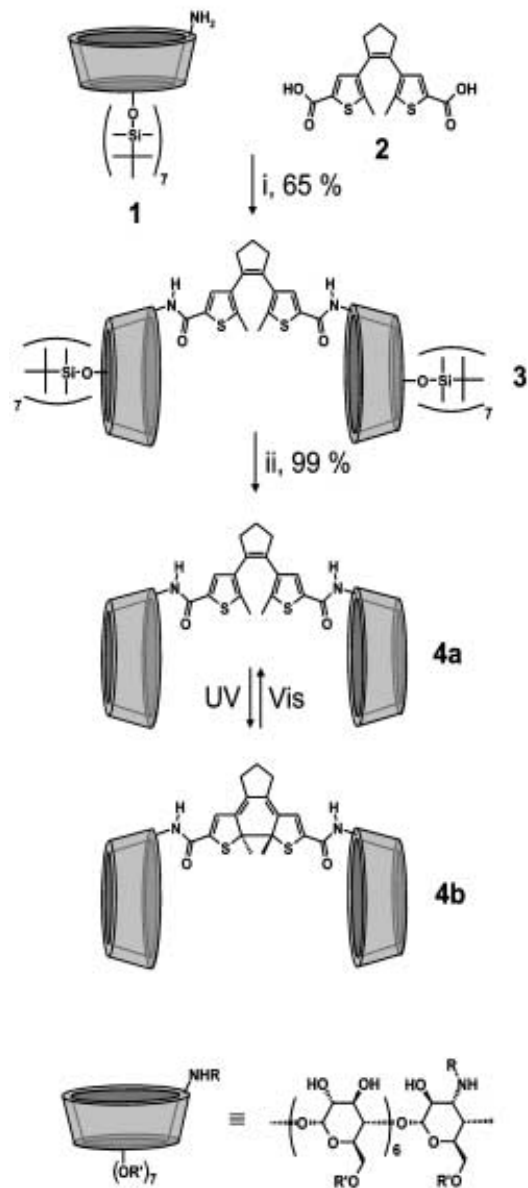
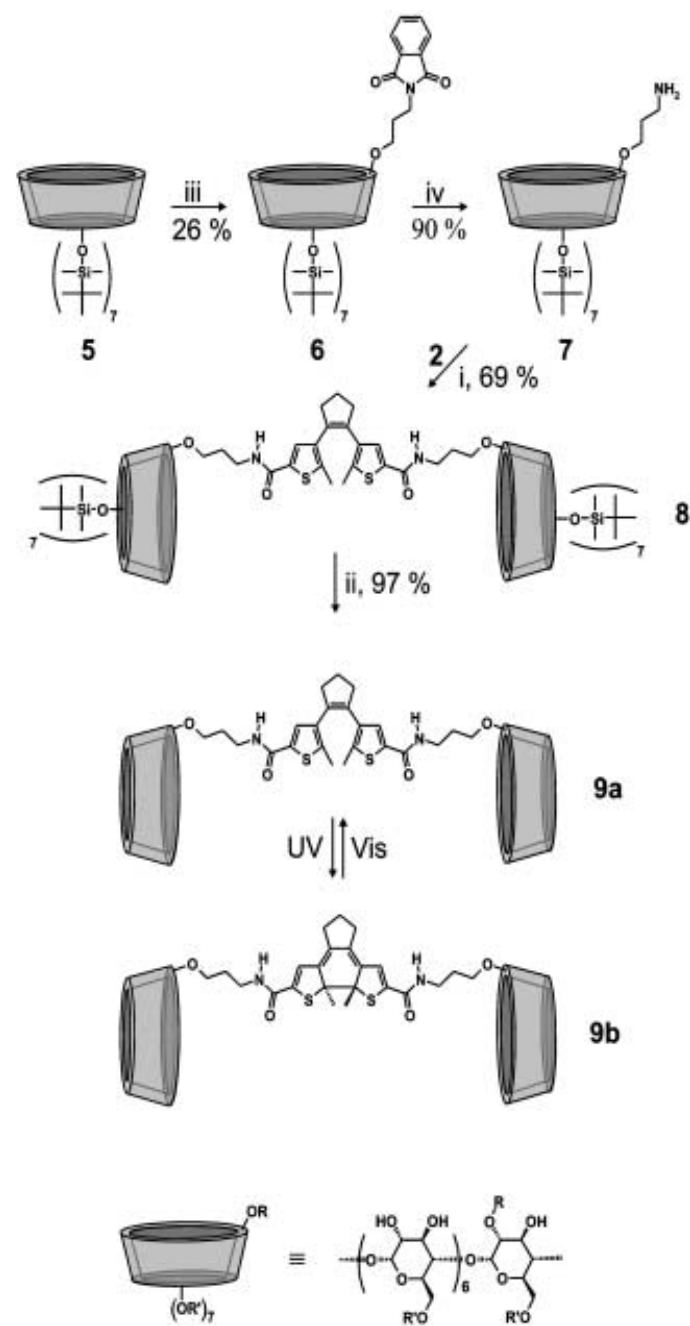

Scheme 1. Synthesis routes for dimers 4 and 9. i) HBTU, DIPEA, THF; ii) TFA; iii) $\mathrm{LiH}, n$-(3-bromopropyl)phthalimide, THF; iv) $\mathrm{H}_{2} \mathrm{NNH} \cdot \mathrm{H}_{2} \mathrm{O}$, EtOH. DIPEA $=N, N$-diisopropylethylamine; $\quad H B T U=O$-(benzotriazol-1-yl)- $N, N, N^{\prime}, N^{\prime}$-tetramethyluronium hexafluorophosphate; $\quad$ THF $=$ tetrahydrofuran; TFA $=$ trifluoroacetic acid.

reacted 5 and mono- and bis-functionalized cyclodextrin species. Separation by column chromatography gave the monophthalimide 6 in $26 \%$ yield. Alkylation of the $\mathrm{OH}$ groups of cyclodextrin does not alter the stereochemistry of the glucose units and leaves the shape of the cavity unchanged. Removal of the phthalimide moiety by treatment with hydrazine gave the $\beta$-cyclodextrin propylamine $\mathbf{7}$ in $90 \%$ yield after column chromatography. $\beta$-Cyclodextrin derivative $\mathbf{7}$ has previously been synthesized by alkylation of the 2-O-position with 3-azidopropyl tosylate and subsequent reduction of the azide functionality to an amine by treatment with $\mathrm{H}_{2}$ and $\mathrm{Pd} / \mathrm{C}^{[21]}$ However, we prefer the alternative synthesis route depicted in Scheme 1 because of the ease of purification of the statistical mixture by column chromatography and the commercial availability of the propylamine precursor. Coupling of $\mathbf{2}$ and $\mathbf{7}$ gave a $69 \%$ yield of the TBDMS-protected dimer $\mathbf{8}$, which was converted into the water-soluble dimer $\mathbf{9}$ in near-quantitative yield.

The diastereotopic hydrogen atoms of the cyclopentene bridge in dimer 9 appear as a single signal in the ${ }^{1} \mathrm{H}$ NMR spectrum of the compound. It appears that introduction of the propyl chains spaces the $\beta$-cyclodextrin cavities and the dithienylethene unit apart and thereby reduces the influence of the chiral cyclodextrin cavities on the diastereotopic hydrogen atoms.

Switching behavior of the dimers: The photochromic behavior of the dimers was studied by irradiation of the compounds with a high-pressure mercury lamp with band-pass filters. Photochemical reactions were monitored by UV/Vis and ${ }^{1} \mathrm{H}$ NMR spectroscopy. The absorption spectrum of dimer 9 (Figure 1 ) is very similar to that of dimer $4^{[14]}$ and is typical for the type of dithienylethene moiety used for the spacing of the dimers. ${ }^{[15]}$ Aqueous solutions of the open forms of both dimers showed strong absorption in the UV region, with absorption maxima at 267 and $254 \mathrm{~nm}$ for dimers $4 \mathbf{a}$ and $9 \mathbf{a}$, respectively. The colorless aqueous solutions turned red upon irradiation at $313 \mathrm{~nm}$ and an absorption band appeared around $344 \mathrm{~nm}$, together with a broad absorption band in the visible region of the absorption spectra with a maximum at $524 \mathrm{~nm}$ for both dimer $\mathbf{4 b}$ and $\mathbf{9 b}$.

$\mathrm{UV} / \mathrm{Vis}$ spectra recorded before reaching the photostationary state showed sharp isosbestic points indicative of the presence of only two, interchanging species. This deduction 


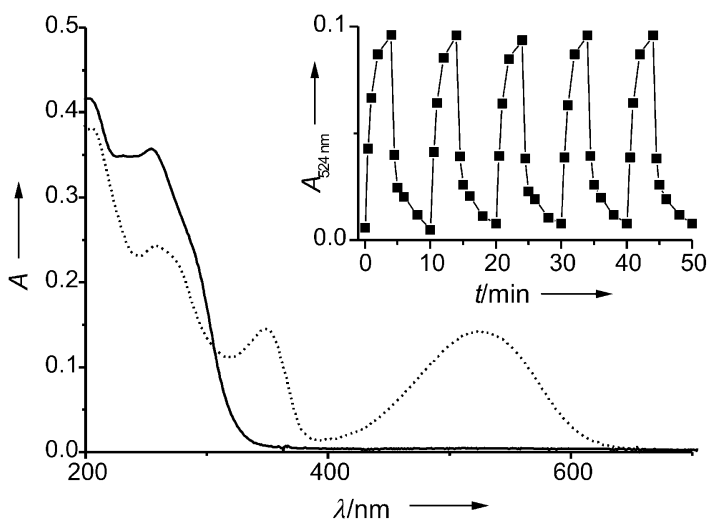

Figure 1. Absorption spectra of $\mathbf{9}(19 \mu \mathrm{M})$ in water before $(\mathbf{9 a},-)$ and after $(\mathbf{9 a} / \mathbf{9 b}$ photostationary state (PSS) mixture, .....) photoirradiation with $313 \mathrm{~nm}$ light. The inset depicts the absorbance at $524 \mathrm{~nm}$ during alternate irradiation at 313 and over $460 \mathrm{~nm}$.

was confirmed by ${ }^{1} \mathrm{H}$ NMR spectra showing a clean conversion into a single new product with $C_{2}$ symmetry upon irradiation. The signals of the thienyl hydrogen atoms underwent a very pronounced upfield chemical shift $(1.0 \mathrm{ppm}$ for dimer 4 and $0.7 \mathrm{ppm}$ for dimer 9), which indicates loss of the aromatic character of the thienyl moiety. These spectral changes are characteristic for the formation of the closed forms of the dimers. As a result of the nonzero absorption of the closed forms in the UV region, both ring-closure and ring-opening take place during photoexcitation in the UV region, which leads to formation of a photostationary state mixture. The absorption spectrum of the PSS mixture of $9 \mathbf{a}$ / 9b is shown in Figure 1. The composition of this mixture can be obtained by ${ }^{1} \mathrm{H}$ NMR spectroscopy or by modeling the UV/Vis spectra (see below). For both dimers, the PSS formed upon irradiation at $\lambda=313 \mathrm{~nm}$ consisted of $25 \%$ open and $75 \%$ closed form. The PSS mixtures are stable at room temperature in the dark. Irradiation of the PSS mixtures with visible light $(\lambda>460 \mathrm{~nm})$ led to the disappearance of the absorption bands in the visible region and completely restored the absorption spectra of the open forms, which indicates that the photochemical ring-opening/ring-closure process is fully reversible. The inset in Figure 1 shows the absorption at $524 \mathrm{~nm}$ during alternate irradiation at $\lambda=$ $313 \mathrm{~nm}$ and at $\lambda>460 \mathrm{~nm}$. Such alternated switching did not lead to any noticeable decomposition of the photochromic unit after five cycles, which demonstrates the excellent fatigue-resistance $^{[9]}$ of compounds 4 and $\mathbf{9}$. The results obtained with dimers $\mathbf{4}$ and $\mathbf{9}$ are comparable to those obtained with similar dithienylethene switches and indicate that the coupling and close proximity of the cyclodextrin cavities does not interfere with the switching process and that the charac- teristics of the dithienylethene tether are maintained in the cyclodextrin dimers. ${ }^{[15]}$

UV/Vis modeling: Modeling of the UV/Vis spectra of a dimer to directly determine the composition of a mixture of its open and closed forms is an easy and practical alternative to the generally used method of integration of the characteristic thiophene proton signals in the ${ }^{1} \mathrm{H}$ NMR spectra. The $\mathrm{UV} / \mathrm{Vis}$ spectra were modeled by fitting a set of Gaussians to the absorption bands in the spectra of the open forms of the dimers. We assumed that the bands with decreasing intensity that appear between 250 and $310 \mathrm{~nm}$ stem only from the open forms. Spectra of irradiated samples were fitted with this set of Gaussians for the open form and with a second set of Gaussians below $250 \mathrm{~nm}$ and at around 350 and $520 \mathrm{~nm}$ that represent the closed form of the dimer. By fitting ten or more UV/Vis spectra of each dimer recorded at different irradiation times $(313 \mathrm{~nm})$, the extinction coefficients and the full absorption spectra of the closed forms of the dimers could be calculated (see Table 1).

The top part of Figure 2 shows the recorded and modeled absorption spectra of the open form and PSS mixture of dimer 4, and the calculated absorption spectrum of the closed form $\mathbf{4 b}$. The sets of Gaussians that constitute the calculated absorption spectra of the open and closed forms of $\mathbf{4}$ are shown in the lower half of Figure 2. Equally good fits were obtained for dimer $\mathbf{9}$ (data shown in Table 1).

Knowledge of the extinction coefficients of both the open and closed forms of the dimers allowed us to determine the ratio of open to closed forms present from a single UV/Vis spectrum. Control experiments showed a good correlation between ratios determined by integration of the thiophene peaks in ${ }^{1} \mathrm{H}$ NMR spectra and those found by modeling the UV/Vis spectra. ${ }^{[22]}$

Complexation studies: We used meso-tetrakis(4-sulfonatophenyl)porphyrin (TSPP) as a guest molecule for the binding studies. The binding of TSPP by $\beta$-cyclodextrin ${ }^{[23]}$ and $\beta$ cyclodextrin dimers ${ }^{[19,24]}$ has been well studied. TSPP is especially interesting because of its symmetry, which imposes a well-defined symmetrical binding mode on the molecule. TSPP has four sulfonatophenyl moieties attached to the porphyrin ring, which functions as a flat and rigid platform. The four sulfonatophenyl moieties offer a total of four available binding sites for cyclodextrin complexation. Previous studies have shown, however, that native $\beta$-cyclodextrin binds TSPP in a 2:1 ratio and complexes two opposite 4-sulfonatophenyl moieties. ${ }^{[23 a]}$ Complexation of two adjacent binding sites is sterically less favorable and gives rise to weaker complexation. $^{[25]}$

Table 1. Parameters for the sets of Gaussians used for fitting the absorption spectra of 4 and $9 .^{[a]}$

\begin{tabular}{|c|c|c|c|c|c|c|c|c|c|c|c|}
\hline \multicolumn{3}{|c|}{$4 a$} & \multicolumn{3}{|c|}{$4 b$} & \multicolumn{3}{|c|}{$9 \mathbf{a}$} & \multicolumn{3}{|c|}{$9 b$} \\
\hline$\lambda_{\max }$ & width & $\varepsilon_{\max }$ & $\lambda_{\max }$ & width & $\varepsilon_{\max }$ & $\lambda_{\max }$ & width & $\varepsilon_{\max }$ & $\lambda_{\max }$ & width & $\varepsilon_{\max }$ \\
\hline 195.5 & 57.2 & 23.7 & 171.3 & 105.6 & 12.6 & 197.2 & 26.5 & 25.2 & 207.5 & 15.9 & 17.2 \\
\hline 266.3 & 14.0 & 17.6 & 208.6 & 10.0 & 10.6 & 251.8 & 19.1 & 15.2 & 264.5 & 34.8 & 11.5 \\
\hline 315.2 & 11.5 & 4.3 & 343.2 & 15.3 & 10.0 & 286.9 & 19.4 & 11.2 & 346.1 & 19.7 & 11.4 \\
\hline & & & 521.2 & 47.4 & 11.5 & & & & 520.3 & 48.2 & 11.7 \\
\hline
\end{tabular}

[a] $\lambda_{\max }[\mathrm{nm}]$, width $[\mathrm{nm}], \varepsilon_{\max }\left[10^{3} \mathrm{~cm}^{-1} \mathrm{M}^{-1}\right]$. 

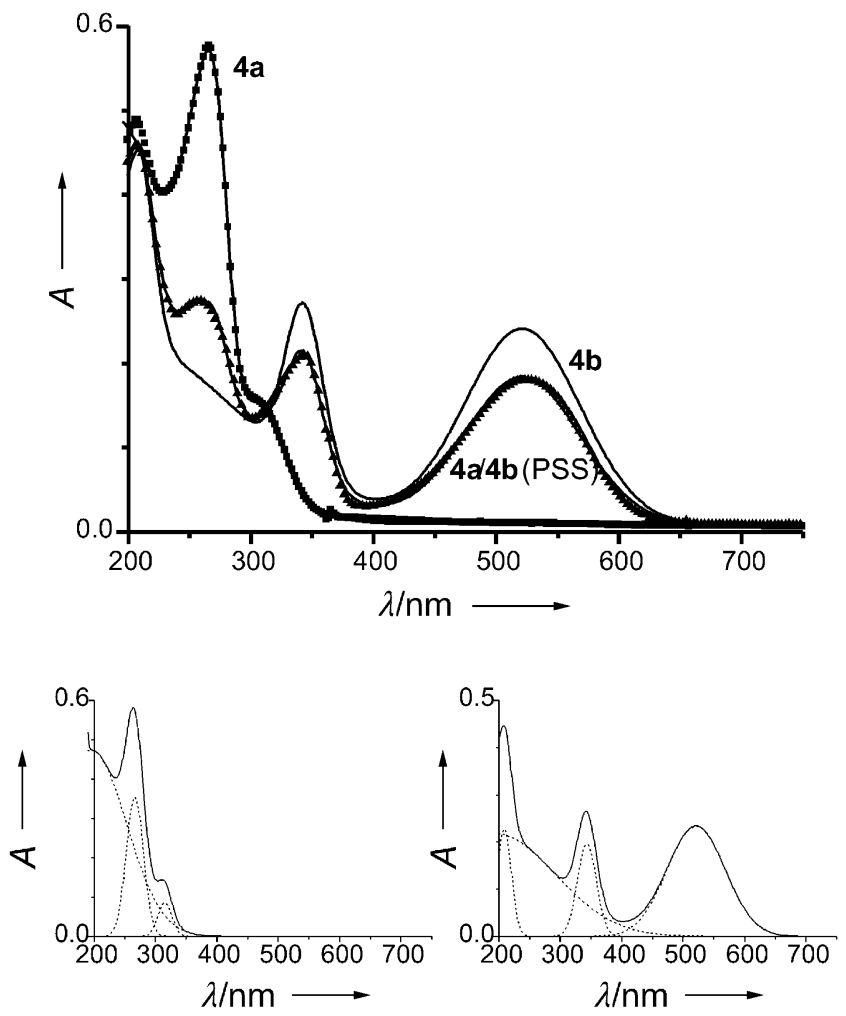

Figure 2. Top: measured (markers) and modeled (lines) absorption curves of $\mathbf{4}(19 \mu \mathrm{M})$ in water $(\mathbf{4 a}, \mathbf{a}$; PSS mixture of $\mathbf{4 a / 4 b}, \mathbf{\Delta} ; \mathbf{4 b},-)$. Bottom: Set of Gaussians (---) that constitute the calculated absorption spectra (-) of $\mathbf{4 a}$ (left) and $\mathbf{4 b}$ (right).

Binding of TSPP by the open and closed forms of the dimers 4 and 9 was studied by using isothermal titration microcalorimetry. The binding curves of the open forms of the dimers were fitted to a 1:1 binding model with the association constant, $K$, and the binding enthalpy, $\Delta H^{\circ}$, as independent fitting parameters. To determine the thermodynamic binding parameters for the binding of TSPP by the closed forms of the dimers, $\mathbf{4 b}$ and $\mathbf{9 b}$, calorimetric studies were performed with mixtures of the open and closed forms of each dimer. The compositions of the mixtures were determined beforehand by UV/Vis spectroscopy in combination with the UV/Vis modeling technique described above. Binding curves obtained for these mixtures were fitted by calculating the net heat effects for the binding of TSPP to the open form of the dimer from the composition of the mixture and the binding parameters obtained from the titration of TSPP with the open form, while optimizing the binding constant and enthalpy of the closed form. For comparison, microcalorimetry experiments were performed to study the complexation of TSPP by native $\beta$-cyclodextrin. The obtained thermodynamic parameters are summarized in Table 2.

In Figure 3, the net heat evolved per injection of TSPP is plotted against the molar ratio of guest to host for the titrations of TSPP with dimer 4. Titration of TSPP with the open form of the dimer, $\mathbf{4 a}$, gave a binding curve typical of 1:1 complex formation (Figure 3, top). The obtained thermodynamic parameters $\left(K\right.$ and $\left.\Delta H^{\circ}\right)$ are indicative of a strongly bound 1:1 complex in which both $\beta$-cyclodextrin cavities par-
Table 2. Thermodynamic parameters of the complexation of TSPP by the open and closed forms of $\mathbf{4}$ and $\mathbf{9}$, as determined by isothermal titration microcalorimetry at $298 \mathrm{~K}$.

\begin{tabular}{llllr}
\hline host & $\begin{array}{l}K \\
\left(\mathrm{M}^{-1}\right)\end{array}$ & $\begin{array}{l}\Delta G^{\circ} \\
\left(\mathrm{kcalmol}^{-1}\right)\end{array}$ & $\begin{array}{l}\Delta H^{\circ} \\
\left(\mathrm{kcal} \mathrm{mol}^{-1}\right)\end{array}$ & $\begin{array}{l}T \Delta S^{\circ} \\
\left(\mathrm{kcal} \mathrm{mol}^{-1}\right)\end{array}$ \\
\hline$\beta-\mathrm{CD}^{[\mathrm{a}]}$ & $(3.1 \pm 0.4) \times 10^{4}$ & $-6.1 \pm 0.1$ & $-4.3 \pm 0.2$ & $1.8 \pm 0.3$ \\
4a & $(3.3 \pm 0.4) \times 10^{6}$ & $-8.9 \pm 0.1$ & $-12.8 \pm 0.4$ & $-3.9 \pm 0.5$ \\
4b & $(9.7 \pm 1.3) \times 10^{4}$ & $-6.8 \pm 0.1$ & $-5.3 \pm 1.1$ & $1.5 \pm 1.2$ \\
9a & $(3.3 \pm 0.2) \times 10^{6}$ & $-8.9 \pm 0.1$ & $-11.8 \pm 0.8$ & $-2.2 \pm 0.9$ \\
9b & $(1.2 \pm 0.2) \times 10^{6}$ & $-8.3 \pm 0.1$ & $-11.2 \pm 1.0$ & $-2.9 \pm 1.1$ \\
\hline
\end{tabular}

[a] $\beta$ cyclodextrin.
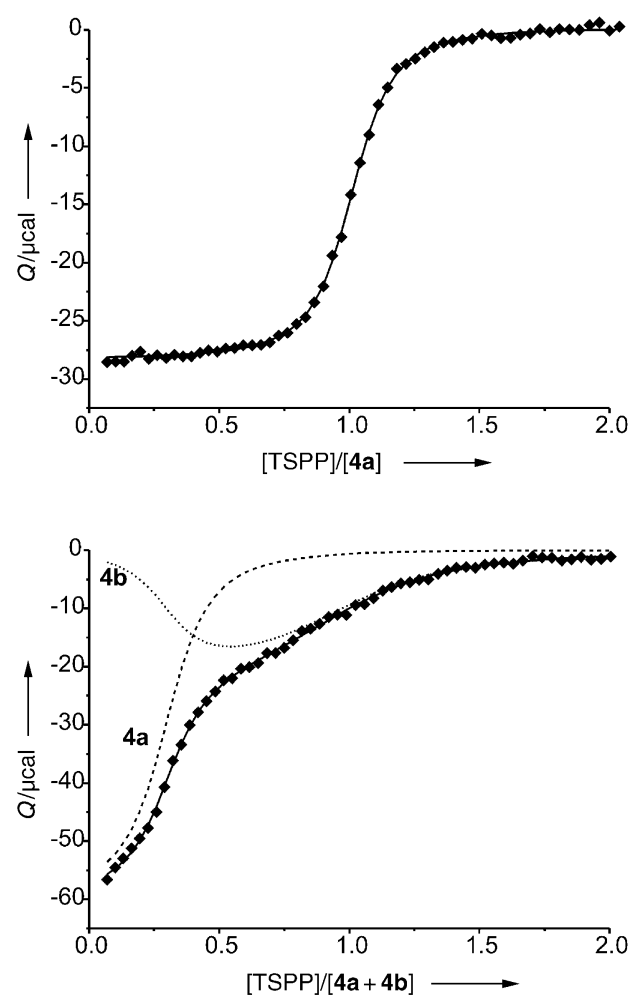

Figure 3. Heat evolved per injection of TSPP plotted against the [TSPP]/ [4] ratio and fit (solid line) to a 1:1 binding model for the calorimetric titrations of TSPP with $\mathbf{4 a}$ (top) and with the PSS mixture of $\mathbf{4}$ (bottom) in water at $298 \mathrm{~K}$. For the PSS mixture, the calculated contributions to the heat profile made by the binding of TSPP by $\mathbf{4 a}(---)$ and $\mathbf{4 b}(\cdots .$.$) are$ shown.

ticipate in binding; the measured $K$ value is substantially larger than that for the binding of $\beta$-cyclodextrin to TSPP and the binding enthalpy is close to double that measured with a single cyclodextrin cavity. The negative entropy value accompanying the binding of TSPP by $\mathbf{4} \mathbf{a}$ can be attributed to enthalpy-entropy compensation ${ }^{[26]}$ and restriction of the mobility of the spacer in the dimer upon binding to the guest molecule.

The plot in the bottom half of Figure 3 shows the titration curve for the titration of TSPP with the PSS mixture of the open and closed forms of dimer 4. The shape of the obtained titration curve suggests the presence of two superimposed binding curves, as witnessed by an inflection point at a concentration ratio of around 0.3 and another slight inflection at a ratio of around 1 . The former value nicely corresponds to the fraction of the open form of $\mathbf{4 a}$ in the PSS 
mixture. We therefore attribute the initial strong binding indicated by the binding curve to binding of TSPP to the open form of the dimer. A fit of the titration curve (as described above) taking into account the previously determined parameters for the binding of the open form of the dimer, $\mathbf{4 a}$, gave the thermodynamic parameters for the binding of TSPP with the closed form, $\mathbf{4 b}$. As can be seen from Table 2 and is evident from the titration curves, there is a marked difference between the binding of TSPP with the open form of dimer $\mathbf{4}$ and that with the closed form. The binding constant for binding of TSPP to the open form, $\mathbf{4 a}$, is greater than that for binding to the closed form, $\mathbf{4 b}$, by a factor of 35. In fact, all the thermodynamic parameters of the binding of TSPP by the closed dimer $\mathbf{4 b}$ are indicative of a single $\beta$ cyclodextrin-TSPP interaction and are in the same range as the thermodynamic values obtained for the complexation of TSPP by native $\beta$-cyclodextrin. These results suggest that the closed form does not sterically allow 1:1 binding of the dimer to TSPP with both cavities strongly binding a sulfonatophenyl ring in a cooperative fashion.

With the introduction of the propyl spacer between the $\beta$ cyclodextrin cavities and the dithienylethene moiety in dimer 9, the difference in binding affinity between the open and closed forms is lost. As can be seen from the thermodynamic parameters obtained for the binding of TSPP with $9 \mathbf{a}$ and $9 \mathbf{b}$ (Table 2), very similar binding enthalpy and entropy values were obtained for both the open and closed forms of dimer 9. The measured binding enthalpies indicate that both dimers bind TSPP through two $\beta$-cyclodextrin cavities. It seems that the flexible propyl spacers provide enough rotational freedom for the dimers to overcome the rigidity imposed by closure of the dithienylethene moiety. As observed for $4 \mathbf{a}$, dimers $9 \mathbf{a}$ and $9 \mathbf{b}$ have negative binding entropies. It appears that the strong binding employing both cavities restricts the mobility of both host and guest within the complex.

Nolte et al. have found both $1: 1$ and 2:2 binding modes for the binding of TSPP by $\beta$-cyclodextrin dimers. ${ }^{[24 b]}$ Flexible alkyl-chain-tethered $\beta$-cyclodextrin dimers displayed mostly 1:1 binding, whereas the sigmoidal shape of the fluorescence titration curve for the binding of TSPP by a relatively rigid $2,2^{\prime}$-bipyridine-tethered $\beta$-cyclodextrin dimer was explained by a $2: 2$ binding mode. The inflection point in our calorimetric titration curves does not exclude the possibility of 2:2 binding. A 2:2 binding mode would, however, be expressed as a higher concentration dependence of binding than that observed with a 1:1 binding mode. To determine the binding modes of the open and closed forms of dimers 4 and 9, all titrations were performed at three different concentrations. For all four dimers, the obtained titration curves were best fitted with a 1:1 binding model. Additional fluorescence titrations were performed with the relatively rigid open dimer $4 \mathbf{a}$ and the results are shown in Figure 4. The binding of TSPP by the cavities of dimer $4 \mathbf{a}$ resulted in an exponential decrease in fluorescence intensity and a titration curve that corresponds to the formation of a 1:1 complex. No sigmoidal character of the titration curve was observed that would imply a 2:2 binding mode. A fit of the curve to a 1:1 model gave a binding constant of $1 \times 10^{7} \mathrm{M}^{-1}$, which is in

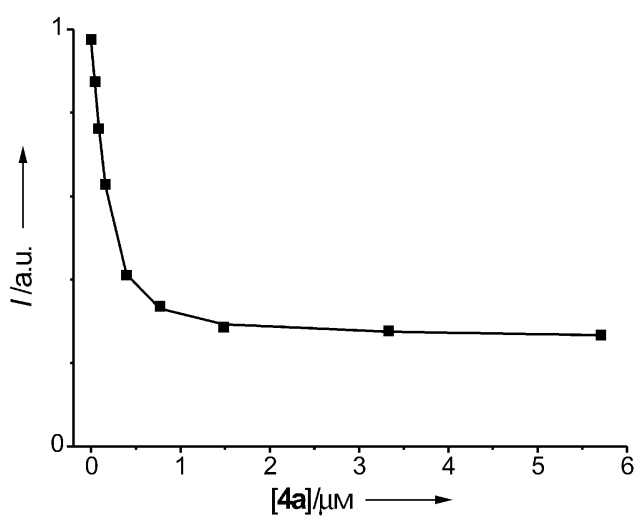

Figure 4. Fluorescence titration curve and 1:1 binding model fit for the complexation of TSPP $\left(2.0 \times 10^{-7} \mathrm{M}\right)$ by $\mathbf{4 a}$.

good agreement with the binding constant found by microcalorimetry. The shape of the titration curve for the binding of TSPP by $\mathbf{4 b}$ could not be determined. Fluorescence titrations performed with a PSS mixture of $\mathbf{4}$ were dominated by the more strongly binding $\mathbf{4 a}$.

Another point for consideration when studying $\beta$-cyclodextrin dimer-TSPP complexes is the binding geometry of the guest. Both syn and anti 1:1 binding geometries have been observed in complexes of $\beta$-cyclodextrin dimers with TSPP depending on the tether length and flexibility. ${ }^{[24 b]}$ The peak splitting of the porphyrin ring protons in the ${ }^{1} \mathrm{H}$ NMR spectrum of such a complex can be used to elucidate the binding geometry of TSPP with the cyclodextrin dimer. However, the complexes of TSPP with our dimers $4 \mathbf{a}$ and 9a have very complicated ${ }^{1} \mathrm{H}$ NMR spectra in which both the signals from TSPP and those of the dithienylethene moieties of the dimers show extensive splitting and broadening. Even at $-10^{\circ} \mathrm{C}$ in a mixture of $\mathrm{MeOD}$ and $\mathrm{D}_{2} \mathrm{O}$ the spectra are too complicated and the signals too broad to be exploited for assignment of the binding geometry. CPK (space-filling) models suggest that dimers $\mathbf{4}$ and $\mathbf{9}$ are able to bind TSPP in the sterically less demanding anti geometry, both in their open and closed forms. It is therefore likely that both dimers bind TSPP in an anti fashion and that the relatively slow exchange process and possibly asymmetric positioning of the dithienylethene units over the porphyrin face lead to the complicated ${ }^{1} \mathrm{H}$ NMR spectra.

Molecular modeling: Molecular modeling was used to further validate our interpretation of the complexation differences observed between the dimers. The $\beta$-cyclodextrin dimer models were built by using the data for $\beta$-cyclodextrin available from the Cambridge Crystallographic Database and the X-ray crystal structure of 5,5'-(dialdehydodithienyl)cyclopentene, which is a precursor used for the synthesis of 2 (Figure 5).

Figure 6 shows the energy-minimized structures of the complexes of TSPP with the open and closed forms of dimers $\mathbf{4}$ and $\mathbf{9}$. The structure obtained for the complex of the open dimer 4a with TSPP (Figure 6, top left) suggests that the dimer is able to form a strong complex with TSPP that employs both cyclodextrin cavities. The rotational free- 


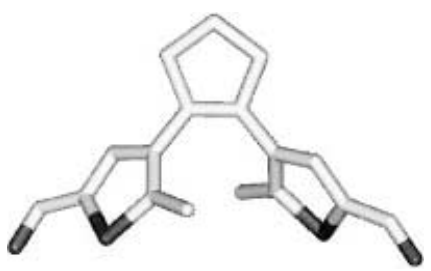

Figure 5. X-ray crystal structure of 5,5'-(dialdehydodithienyl)cyclopentene. Hydrogen atoms are omitted for clarity.

dom in the open form of the dithienylethene moiety allows the dimer to fold over the porphyrin guest and enables both $\beta$-cyclodextrin cavities to participate in binding. Most importantly, both cavities are shifted well over the sulfonatophenyl moieties and even over part of the porphyrin base and therefore shield the most hydrophobic parts of TSPP from the bulk water. The more hydrophilic sulfonate groups stick out from the primary sides of the $\beta$-cyclodextrin cavities.

The structure obtained for the closed form of the dimer, 4b, complexed with TSPP (Figure 6, top right) indicates that the $\beta$-cyclodextrin cavities are spaced too far apart from each other by the rigid closed form of the dithienylethene tether to allow both cavities to contribute to the binding of TSPP to the same extent as in $4 \mathbf{a}$. The dithienylethene moiety is situated diagonally over the porphyrin base in the minimized structure, which minimizes the distance between the two $\beta$-cyclodextrin cavities. Nevertheless, even in this conformation it is impossible for both cavities to completely shift over the sulfonatophenyl rings or to interact with and shield the porphyrin base fully. This model corroborates the conclusions made from the calorimetric data for TSPP and 4b that their binding is mainly due to a single $\beta$-cyclodextrin-sulphonatophenyl interaction, possibly with a small con- tribution from the second $\beta$-cyclodextrin cavity. It is likely that the guest moves back and forth between the two cavities in the complex with $\mathbf{4 b}$.

Dimers $9 \mathbf{a}$ and $\mathbf{9 b}$ are both able to tightly bind TSPP (Figure 6 , bottom). In both complexes, both $\beta$-cyclodextrin cavities are shifted partly over the porphyrin base, which ensures strong interaction with and shielding of the hydrophobic parts of the guest molecule. The flexible propyl spacers between the dithienylethene moiety and the $\beta$-cyclodextrin cavities are able to compensate for the rigidity imposed by the closed dithienylethene switch and allow the $\beta$-cyclodextrin cavities to come into close proximity with each other, which enables the dimer to tightly bind TSPP. The similar binding modes found for the binding of TSPP by the open and closed forms of dimer $\mathbf{9}$ are reflected in the similar thermodynamic parameters found for complex formation by these dimers.

Phototriggered release and uptake: UV/Vis spectroscopy allows real-time determination of the ratio of uncomplexed to complexed TSPP upon irradiation of dimer/TSPP mixtures. The absorption maximum of TSPP is red-shifted and the absorbance decreases upon complexation by cyclodextrin. ${ }^{[23 \mathrm{~b}]}$ Figure 7 shows part of the absorption spectra of TSPP complexed with dimers $\mathbf{4 a}$ and $9 \mathbf{a}$ upon irradiation at $313 \mathrm{~nm}$. The absorption maximum at $413 \mathrm{~nm}$ of TSPP in aqueous solution was red-shifted to 418 and $420 \mathrm{~nm}$ upon addition of the dimers $4 \mathbf{a}$ and $9 \mathbf{a}$, respectively, which is indicative of complex formation between TSPP and the dimers. The absorption peak of complexed TSPP decreased upon irradiation of its complex with dimer $\mathbf{4 a}$ at $313 \mathrm{~nm}$, and simultaneously absorption by uncomplexed TSPP increased; an isosbestic point was observed at $416 \mathrm{~nm}$ (Figure 7, top). Upon closing of the dithienylethene moiety, TSPP appears

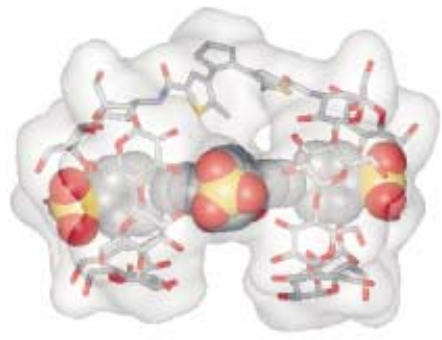

4a-TSPP

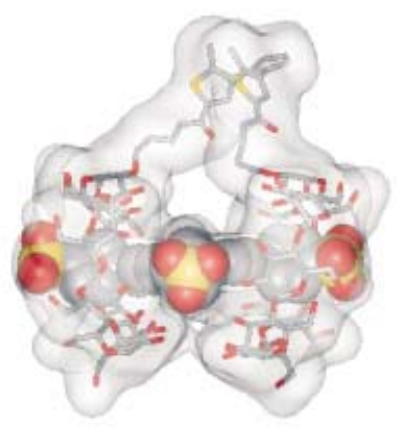

9a-TSPP
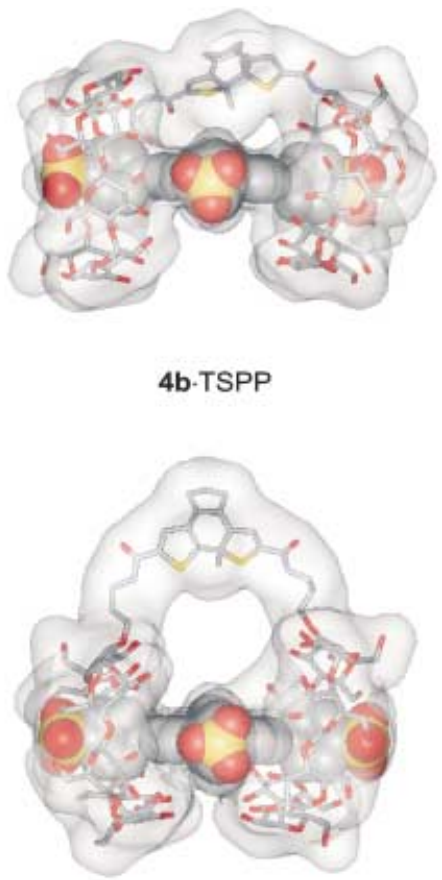

9b-TSPP
Figure 6. CHARMM-minimized structures of the complexes of TSPP with dimers 4 and 9. to be released from the $\beta$-cyclodextrin dimer. This result is in agreement with the data obtained by microcalorimetry, which indicates that TSPP is strongly bound by $\mathbf{4 a}$ at the concentrations used for the UV/Vis measurement, whereas the closed form $\mathbf{4 b}$ does not significantly bind TSPP at these concentrations.

Irradiation of the complex of dimer $9 \mathbf{a}$ and TSPP at $313 \mathrm{~nm}$ did not lead to any noteworthy release of TSPP (Figure 7, bottom). A slight increase in the absorbance at $420 \mathrm{~nm}$ was observed, which might indicate that the molecular environment around the complexed TSPP molecule changes upon closing of the dithienylethene tether, but the absorbance by uncomplexed 

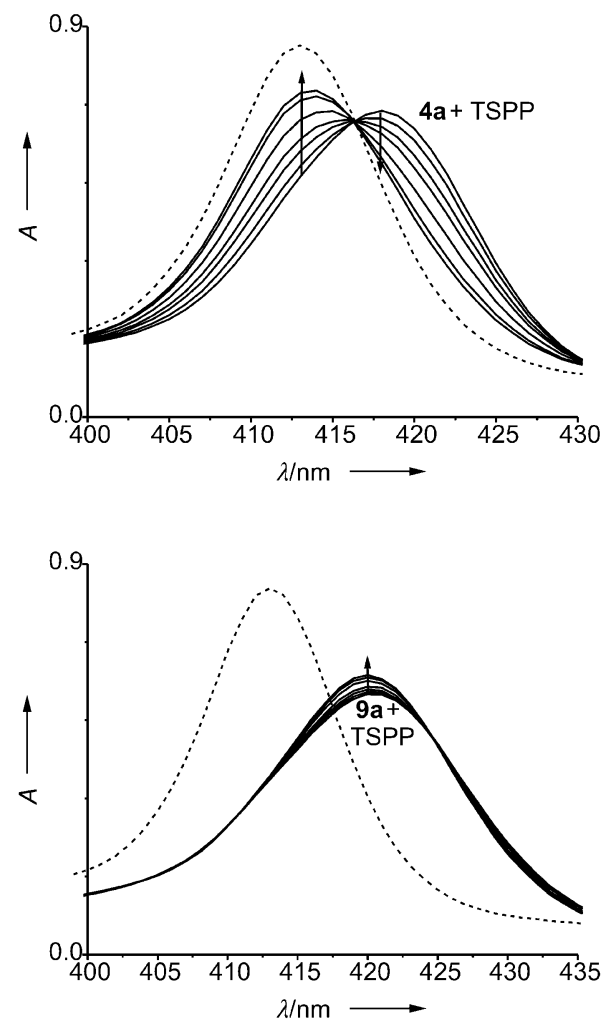

Figure 7. Absorption spectra (0-25 min) of 2- $\mu \mathrm{M}$ solutions of TSPP complexed with $4 \mathbf{a}$ (top) and 9a (bottom) in water upon irradiation at $\lambda=$ $313 \mathrm{~nm}$. The spectrum of $2 \mu \mathrm{M}$ TSPP in water is also shown (....).

TSPP at $413 \mathrm{~nm}$ remained constant during the experiment. From these results it can be concluded that both the open and closed forms of dimer 9 bind TSPP strongly at these concentrations, which is in good agreement with the microcalorimetric data.

Figure 8 depicts the absorbance of dimer $4 \mathbf{a}$ and uncomplexed TSPP at their absorption maxima (267 and $413 \mathrm{~nm}$, respectively) upon alternate irradiation of a 1:1 solution of dimer 4 and TSPP (both $2.0 \times 10^{-6} \mathrm{M}$ ) at $313 \mathrm{~nm}$ and at above $460 \mathrm{~nm}$. Irradiation at $313 \mathrm{~nm}$ led to the conversion of $\mathbf{4 a}$ into $\mathbf{4 b}$, which resulted in a decrease in absorbance by $4 \mathbf{a}$.

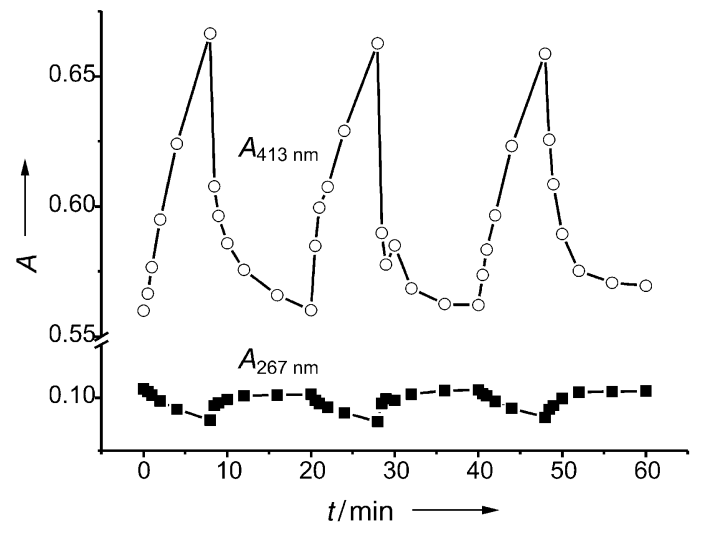

Figure 8. Absorbance at 267 ( $\mathbf{m}$, absorption maximum of $\mathbf{4 a}$ ) and $413 \mathrm{~nm}$ ( $O$, absorption maximum of uncomplexed TSPP) of a 2- $\mu$ M solution of the complex of $\mathbf{4 a}$ with TSPP upon alternate irradiation at 313 and $>460 \mathrm{~nm}$.
At the same time, TSPP was released from the $\beta$-cyclodextrin cavities, which led to an increase in the absorbance of free TSPP. Irradiation of the solution with visible light regenerated the open form of the dimer and simultaneously led to the uptake of uncomplexed TSPP from solution until the initial equilibrium between TSPP and 4 a was completely restored. Control experiments showed no significant reduction of the absorbance of free TSPP during irradiation at 313 or $460 \mathrm{~nm}$. As is evident from Figure 8, the release and uptake cycle can be repeated several times without significant degradation. Within the limits of this system, any ratio of free to uncomplexed TSPP can be achieved simply by tuning the relative amounts of $\mathbf{4 a}$ and $\mathbf{4 b}$, which can be regulated by photoirradiation.

\section{Conclusions}

The tethering of two $\beta$-cyclodextrin cavities with a dithienylethene moiety gives access to photoswitchable $\beta$-cyclodextrin dimers. These dimers can be switched between a relatively flexible (open) and a more rigid (closed) form by irradiation with light. The switching properties of the dithienylethene unit are unaffected by covalent linkage to the $\beta$-cyclodextrin cavities and the switching process is completely reversible and fatigue resistant. Depending on the molecular architecture, the switching of the dithienylethene unit between the open and closed forms can lead to a change in the binding affinity of the dimer for specific guest molecules. The rigidity of the connection between the dithienylethene tether and the $\beta$-cyclodextrin cavities plays an important role in this effect. A certain amount of rigidity is required to allow substantial transfer of the switching effect taking place in the dithienylethene unit to the $\beta$-cyclodextrin dimer as a whole. Effective transfer of the switching process can be achieved by direct coupling of the photochromic unit to the rim of the $\beta$-cyclodextrin cavity and differences in binding affinity between the open and closed form are then obtained. This difference in affinity in turn allows the photocontrolled release and uptake of guest molecules to and from solution and thus makes full control over the ratio of complexed to free guest molecules in solution possible. Photoswitchable $\beta$-cyclodextrin dimers such as $\mathbf{4}$ are interesting candidates for use as photocontrollable (drug) delivery systems and might find application in, for example, photodynamic cancer therapy. ${ }^{[8,27]}$

\section{Experimental Section}

Materials and methods: All chemicals were used as received, unless stated otherwise. Solvents were purified according to standard laboratory methods. ${ }^{[2]}$ Thin-layer chromatography was performed on aluminum sheets precoated with silica gel 60 F254 (Merck). The cyclodextrin spots were visualized by dipping the sheets in $5 \%$ sulfuric acid in ethanol and subsequent heating. Chromatographic separations were performed on silica gel 60 (Merck, 0.040-0.063 mm, 230-240 mesh). 3-Amino-3-deoxyheptakis(6-O-tert-butyldimethylsilyl)- $\beta$-cyclodextrin $(1),{ }^{[16]} 5,5^{\prime}$-dicarboxydithienylethene (2), ${ }^{[15]}$ and heptakis(6- $O$-tert-butyldimethylsilyl)- $\beta$-cyclodextrin $(\mathbf{5})^{[16]}$ were prepared according to literature procedures. 
MALDI-TOF mass spectra were recorded on a PerSpective Biosystems Voyager-DE-RP MALDI-TOF mass spectrometer. NMR spectra were recorded at $25^{\circ} \mathrm{C}$ with a Varian Inova 300 spectrometer. ${ }^{1} \mathrm{H}$ NMR $(300 \mathrm{MHz})$ chemical shifts are given relative to residual $\mathrm{CHCl}_{3}$ (7.25 ppm) or HDO (4.65 ppm). ${ }^{13} \mathrm{C} \mathrm{NMR}(75 \mathrm{MHz})$ chemical shifts are given relative to $\mathrm{CDCl}_{3}\left(77 \mathrm{ppm}\right.$ ) or to $\mathrm{CH}_{3} \mathrm{OD}$ (used as an external standard for samples measured in $\mathrm{D}_{2} \mathrm{O}$ ).

All synthesized compounds containing the dithienylethene moiety are light-sensitive and were therefore handled exclusively in the dark in brown-stained glassware.

TBDMS-protected dithienylethene-tethered $\beta$-cyclodextrin dimer 3: HBTU (218 mg, $0.58 \mathrm{mmol})$ and DIPEA $(0.17 \mathrm{~mL}, 0.96 \mathrm{mmol})$ were added to a cooled solution of $2(67 \mathrm{mg}, 0.19 \mathrm{mmol})$ in dry THF $(50 \mathrm{~mL})$. The solution was stirred for $30 \mathrm{~min}$ and then allowed to warm to room temperature. Compound $\mathbf{1}(929 \mathrm{mg}, 0.48 \mathrm{mmol}$ ) was added and the solution was stirred for 2 days at room temperature. The solvent was removed in vacuo and chloroform was added. The solution was washed twice with $1 \mathrm{~m} \mathrm{HCl}$ and brine. After removal of the solvent, the crude product was purified by gradient column chromatography (ethyl acetate/ ethanol/water, 100:2:1 to 100:8:4) to give $\mathbf{3}$ (open form) as a white powder in $65 \%$ yield. ${ }^{1} \mathrm{H} \mathrm{NMR}\left(\mathrm{CDCl}_{3}\right): \delta=8.15(\mathrm{~d}, J=6.6 \mathrm{~Hz}, 2 \mathrm{H}), 6.96$ (s, 2H), 5.06-4.73 (m, 14H), $4.53(\mathrm{~d}, J=7.3 \mathrm{~Hz}, 2 \mathrm{H}), 4.21-3.41(\mathrm{~m}, 66 \mathrm{H})$, $3.28(\mathrm{t}, J=9.2 \mathrm{~Hz}, 2 \mathrm{H}), 2.99$ (quintet, $J=7.3 \mathrm{~Hz}, 2 \mathrm{H}$ ), 2.48 (quintet, $J=$ $7.3 \mathrm{~Hz}, 2 \mathrm{H}), 1.96(\mathrm{t}, J=7.3 \mathrm{~Hz}, 2 \mathrm{H}), 1.84(\mathrm{~s}, 6 \mathrm{H}), 0.93-0.81(\mathrm{~m}, 124 \mathrm{H})$, $0.05-0.00 \mathrm{ppm}(\mathrm{m}, 84 \mathrm{H}) ;{ }^{13} \mathrm{C} \mathrm{NMR}\left(\mathrm{CDCl}_{3}\right): \delta=166.2,143.9,136.1$, $134.9,133.1,132.1,104.3,102.0-100.2,82.6-79.2,73.9-71.6,62.5-60.4$, 53.6, 37.3, 29.3, 26.0-25.8, 18.3, 14.5, -4.8--5.5 ppm; MS (MALDITOF): $m / z$ : calcd for $[M+\mathrm{Na}]^{+}: 4199.0$; found: 4199.8 .

Dithienylethene-tethered $\beta$-cyclodextrin dimer 4a: TBDMS-protected dimer 3 (210 mg, $0.05 \mathrm{mmol})$ was dissolved in trifluoroacetic acid $(25 \mathrm{~mL})$. The solution was stirred at room temperature for $10 \mathrm{~min}$. The solvent was removed in vacuo. Methanol was added and evaporated in vacuo to azeotropically remove any residual trifluoroacetic acid. The residue was dissolved in water and washed three times with diethylether. After freeze-drying, dimer 4a was obtained as a white solid in $99 \%$ yield. ${ }^{1} \mathrm{H}$ NMR $\left(\mathrm{D}_{2} \mathrm{O}\right): \delta=7.79(\mathrm{~s}, 2 \mathrm{H}), 5.11-5.02(\mathrm{~m}, 14 \mathrm{H}), 4.72(\mathrm{brs}$, $2 \mathrm{H}), 4.22-4.15(\mathrm{~m}, 4 \mathrm{H}), 3.93-3.51(\mathrm{~m}, 64 \mathrm{H}), 3.14$ (quintet, $J=7.1 \mathrm{~Hz}$, $2 \mathrm{H}$ ), 2.77 (quintet, $J=7.1 \mathrm{~Hz}, 2 \mathrm{H}), 2.37(\mathrm{t}, J=7.3 \mathrm{~Hz}, 2 \mathrm{H}), 1.98 \mathrm{ppm}(\mathrm{s}$, $6 \mathrm{H}) ;{ }^{13} \mathrm{C}$ NMR $\left(\mathrm{D}_{2} \mathrm{O}\right): \delta=166.8,143.2,140.3,137.9,136.4,134.8,106.5$, 105.2-104.8, 85.0-84.3, 78.1, 76.6-74.6, 70.9, 63.5-63.3, 54.0, 41.8, 25.8, $17.3 \mathrm{ppm}$; MS (MALDI-TOF): $\mathrm{m} / z$ : calcd for $[M+\mathrm{Na}]^{+}: 2601.8$; found: 2602.1.

Mono-(2-O-(3-propylphthalimide))-heptakis-(6-O-tert-butyldimethylsilyl)-p-cyclodextrin (6): A solution of silylated $\beta$-cyclodextrin 5 (8.6 g, $4.4 \mathrm{mmol}$, dried for $5 \mathrm{~h}$ at $\left.0.05 \mathrm{mmHg}, 80^{\circ} \mathrm{C}\right)$ and $\mathrm{LiH}(31 \mathrm{mg}, 4.0 \mathrm{mmol})$ in THF $(250 \mathrm{~mL})$ was stirred at room temperature for $18 \mathrm{~h}$, followed by $1 \mathrm{~h}$ at reflux. A solution of $N$-(3-bromopropyl)phthalimide (1.1 g, $4.0 \mathrm{mmol})$ in THF $(50 \mathrm{~mL})$ was added dropwise to the reaction mixture, which was kept at reflux for $2 \mathrm{~h}$. The solvent was evaporated in vacuo and the residue was dissolved in $\mathrm{CHCl}_{3}$ and washed twice with water and once with brine. The organic phase was dried over $\mathrm{MgSO}_{4}$ and filtered. The solvent was evaporated in vacuo and the residue was purified by gradient column chromatography (ethyl acetate/ethanol/water, 100:2:1 to $50: 7: 4)$ to give 6 as a white powder in $26 \%$ yield. ${ }^{1} \mathrm{H}$ NMR $\left(\mathrm{CD}_{3} \mathrm{OD}\right)$ : $\delta=7.78(\mathrm{dd}, J=5.5$ and $3.3 \mathrm{~Hz}, 2 \mathrm{H}), 7.70(\mathrm{dd}, J=5.5$ and $3.3 \mathrm{~Hz}, 2 \mathrm{H})$, $5.03(\mathrm{~d}, J=3.3 \mathrm{~Hz}, 1 \mathrm{H}), 4.86(\mathrm{~d}, J=3.3 \mathrm{~Hz}, 6 \mathrm{H}), 3.96-3.46(\mathrm{~m}, 34 \mathrm{H}), 3.36$ $(\mathrm{dd}, J=9.7$ and $3.3 \mathrm{~Hz}, 6 \mathrm{H}), 3.25(\mathrm{t}, J=1.8 \mathrm{~Hz}, 1 \mathrm{H}), 3.17(\mathrm{dd}, J=9.7$ and $3.3 \mathrm{~Hz}, 1 \mathrm{H}), 1.94$ (quintet, $J=6.3 \mathrm{~Hz}, 2 \mathrm{H}), 0.87-0.84(\mathrm{~m}, 63 \mathrm{H}), 0.03-$ $0.00 \mathrm{ppm}(\mathrm{m}, 42 \mathrm{H}) ;{ }^{13} \mathrm{C} \mathrm{NMR}\left(\mathrm{CD}_{3} \mathrm{OD}\right): \delta=169.7,135.1,133.0,123.0$, $103.5,101.8,82.7,82.1,74.3-73.3,71.0,62.9,58.1,35.6,30.4,29.6,26.5$, $18.3,-4.6--4.7 \mathrm{ppm}$; MS (MALDI-TOF): $\mathrm{m} / z$ : calcd for $[M+\mathrm{Na}]^{+}$: 2145.0; found: 2144.8 .

Mono-(2-O-(3-aminopropyl))-heptakis-(6-O-tert-butyldimethylsilyl)- $\beta$-cyclodextrin (7): Hydrazine monohydrate $(0.3 \mathrm{~mL}, 5.7 \mathrm{mmol})$ was added to a solution of $6\left(1.2 \mathrm{~g}, 0.6 \mathrm{mmol}\right.$, dried for $5 \mathrm{~h}$ at $\left.0.05 \mathrm{mmHg}, 80^{\circ} \mathrm{C}\right)$ in EtOH $(50 \mathrm{~mL})$. The solution was stirred at reflux for $8 \mathrm{~h}$. The solvent was evaporated in vacuo and $\mathrm{CHCl}_{3}$ was added. The organic phase was washed with $1 \mathrm{~m}$ aqueous $\mathrm{HCl}, 1 \mathrm{~m}$ aqueous $\mathrm{NaOH}$, and brine. The solvent was evaporated in vacuo and the residue was purified by gradient column chromatography (ethyl acetate/ethanol/water, 100:2:1 to 50:15:8) to give 7 as a white powder in $90 \%$ yield. ${ }^{1} \mathrm{H} \mathrm{NMR}\left(\mathrm{CDCl}_{3}\right): \delta=5.06(\mathrm{~d}$, $J=2.6 \mathrm{~Hz}, 1 \mathrm{H}), 4.92-4.85(\mathrm{~m}, 6 \mathrm{H}), 4.18-3.35(\mathrm{~m}, 38 \mathrm{H}), 3.22(\mathrm{dd}, J=10.3$ and $2.6 \mathrm{~Hz}, 1 \mathrm{H}), 2.29(\mathrm{brs}, 2 \mathrm{H}), 0.86-0.84(\mathrm{~m}, 63 \mathrm{H}), 0.05-0.00 \mathrm{ppm}(\mathrm{m}$, $42 \mathrm{H}) ;{ }^{13} \mathrm{C} \mathrm{NMR}\left(\mathrm{CDCl}_{3}\right): \delta=102.0-100.2,97.7,82.6-79.2,73.9-71.6$, 62.5-60.4, 40.0, 27.4, 26.0-25.8, 18.3, 14.2, -5.1--5.5 ppm; MS (MALDITOF): $m / z$ : calcd for $[M+\mathrm{H}]^{+}: 1991.0$; found: 1990.8 .

TBDMS-protected dithienylethene-tethered $\beta$-cyclodextrin dimer 8 : HBTU (95 mg, $0.25 \mathrm{mmol})$ and DIPEA $(0.07 \mathrm{~mL}, 0.46 \mathrm{mmol})$ were added to a cooled solution of $\mathbf{2}(30 \mathrm{mg}, 0.09 \mathrm{mmol})$ in dry dimethylformamide $(50 \mathrm{~mL})$. The solution was stirred for $30 \mathrm{~min}$ and then allowed to warm to room temperature. Compound 7 (420 mg, $0.21 \mathrm{mmol})$ was added and the solution was stirred for 3 days at room temperature. The solvent was removed in vacuo and chloroform was added. The solution was washed twice with $1 \mathrm{~m} \mathrm{HCl}$ and brine. After removal of the solvent, the crude product was purified by gradient column chromatography (ethyl acetate/ethanol/water, 100:2:1 to $100: 8: 4)$ to give $\mathbf{8}$ (open form) as a white powder in $69 \%$ yield. ${ }^{1} \mathrm{H}$ NMR $\left(\mathrm{CDCl}_{3}\right): \delta=7.47(\mathrm{~s}, 2 \mathrm{H}), 4.90-4.89$ $(\mathrm{m}, 14 \mathrm{H}), 3.94-3.32(\mathrm{~m}, 76 \mathrm{H}), 3.12(\mathrm{~d}, J=8.8 \mathrm{~Hz}, 2 \mathrm{H}), 2.96$ (quintet, $J=$ $7.3 \mathrm{~Hz}, 2 \mathrm{H}$ ), 2.75 (quintet, $J=7.3 \mathrm{~Hz}, 2 \mathrm{H}$ ), $2.14(\mathrm{t}, J=7.3 \mathrm{~Hz}, 2 \mathrm{H}), 1.96$ $(\mathrm{s}, 6 \mathrm{H}), 1.86$ (brs, 2H), 1.75 (brs, 2H), 0.84-0.81 (m, 124H), 0.04$0.00 \mathrm{ppm}(\mathrm{m}, 84 \mathrm{H}) ;{ }^{13} \mathrm{C} \mathrm{NMR}\left(\mathrm{CDCl}_{3}\right): \delta=163.4,140.6,136.8,135.2$, 134.3, 130.1, 102.4-101.9, 100.1, 81.8-80.7, 73.8-71.8, 61.6-60.6, 38.3, 37.6, 31.9, 29.6, 25.8-25.6, 18.3, 14.6, 14.0, -5.2--5.3 ppm; MS (MALDITOF): $m / z$ : calcd for $[M+\mathrm{Na}]^{+}: 4319.3$; found: 4320.0 .

Dithienylethene-tethered $\boldsymbol{\beta}$-cyclodextrin dimer 9a: TBDMS-protected dimer 8 (155 mg, $0.04 \mathrm{mmol})$ was dissolved in trifluoroacetic acid $(25 \mathrm{~mL})$. The solution was stirred at room temperature for $10 \mathrm{~min}$. The solvent was removed in vacuo. Methanol was added and evaporated in vacuo to azeotropically remove any residual trifluoroacetic acid. The residue was dissolved in water and washed three times with diethylether. After freeze-drying, dimer 9a was obtained as a white solid in $97 \%$ yield. ${ }^{1} \mathrm{H}$ NMR $\left(\mathrm{D}_{2} \mathrm{O}\right): \delta=7.30(\mathrm{~s}, 2 \mathrm{H}), 5.24(\mathrm{~d}, J=3.3 \mathrm{~Hz}, 2 \mathrm{H}), 5.10-5.07$ $(\mathrm{m}, 12 \mathrm{H}), 4.10-3.53(\mathrm{~m}, \mathrm{H}), 3.46(\mathrm{~d}, J=7.7 \mathrm{~Hz}, 2 \mathrm{H}), 2.83$ (quintet, $J=$ $7.1 \mathrm{~Hz}, 4 \mathrm{H}), 2.36(\mathrm{~s}, 6 \mathrm{H}), 2.14(\mathrm{t}, J=7.1 \mathrm{~Hz}, 2 \mathrm{H}), 1.93 \mathrm{ppm}(\mathrm{brs}, 4 \mathrm{H})$; ${ }^{13} \mathrm{C}$ NMR $\left(\mathrm{D}_{2} \mathrm{O}\right): \delta=164.2,140.6,136.0,135.2,133.7,129.0,101.6-100.2$, 81.8-80.4, 73.0-71.2, 59.9-59.6, 38.3, 28.7, 22.6, 13.5 ppm; MS (MALDITOF): $m / z$ : calcd for $[M+\mathrm{Na}]^{+}: 2717.9$; found: 2717.9 .

UV/Vis spectroscopy: UV/Vis spectra were recorded on a Hewlett Packard HP $8452 \mathrm{UV} / \mathrm{Vis}$ spectrophotometer. Irradiation experiments were performed in situ by irradiation of the samples in a 1-cm quartz cuvette in the UV/Vis setup by using a 200-W mercury lamp with a 313-nm band-pass or a 460-nm high-pass filter.

Preparation of PSS mixtures: Solutions of the open form of the dimer (1-10 $\mathrm{mm})$ in Millipore water in a 1-cm quartz cuvette were irradiated with a high-intensity mercury lamp for $10-15 \mathrm{~min}$. UV/Vis spectra of diluted samples were used to follow the photochromic reaction. Once the PSS was reached, samples were freeze-dried to give the PSS mixture as a purple solid.

Calorimetry: Calorimetric titrations were performed at $25^{\circ} \mathrm{C}$ on a Microcal VP-ITC titration microcalorimeter. Sample solutions were prepared in pure water (Millipore Q2). Titrations were performed by adding aliquots of a guest solution to the host solution. The titrant typically contained $0.1-1 \mathrm{~mm}$ guest, while the cell solutions contained $10-100 \mu \mathrm{m}$ host. All calorimetric titrations were corrected for dilution heats by subtraction of the calorimetric dilution experiment results from the calorimetric titration experiment results. The titration results were analyzed with a least-squares curve fitting procedure.

Crystal structure determination: Crystals of 5,5'-(dialdehydodithienyl)cyclopentene were obtained by slow diffusion of methanol into a solution of 5,5'-(dialdehydodithienyl)cyclopentene in dichloromethane. Crystal data: $\mathrm{C}_{17} \mathrm{H}_{16} \mathrm{O}_{2} \mathrm{~S}_{2}, M_{\mathrm{r}}=316.44$, brown crystal, $0.15 \times 0.15 \times 0.30 \mathrm{~mm}$, orthorhombic, space group Pbcn (no. 60), $a=10.9081(10), b=8.2278(10), c=$ $17.231(2) \AA, \quad V=1546.5(3) \AA^{3}, Z=4, \rho_{\text {calcd }}=1.359 \mathrm{~g} \mathrm{~cm}^{-3}, \quad F(000)=664$, $\mu_{\mathrm{MoKa}}=0.345 \mathrm{~mm}^{-1} .42400$ reflections were measured on a Nonius KappaCCD diffractometer on a rotating anode $\left(\lambda_{\mathrm{MoK} \alpha}=0.71073 \AA, T=150 \mathrm{~K}\right.$, $\left.\theta_{\max }=27.5^{\circ}\right), 1776$ of which were unique $\left(R_{\mathrm{int}}=0.0361\right)$. The structure was solved with the SHELXS86 program. ${ }^{[29]} 120$ parameters, which included all hydrogen atom coordinates and anisotropic displacement parameters for all non-H atoms, were refined with the SHELXL-97 program. ${ }^{[30]}$ The displacement parameters of the hydrogen atoms were cou- 
pled to the equivalent displacement parameters of their carrier atoms. The refinement converged at $w R 2=0.0790, w^{-1}=\sigma^{2}\left(F_{\mathrm{o}}^{2}\right)+(0.0400 P)^{2}+$ $0.61 P$ (where $P=\left(\operatorname{Max}\left(F_{\mathrm{o}}^{2} 0\right)+2 F_{\mathrm{c}}^{2}\right) / 3$ ), $R 1=0.0288$ (for $1628 F_{o}>$ $\left.4 \sigma\left(F_{o}\right)\right), S=1.067,-0.24<\Delta \rho<0.29 e \AA^{-3}$.

CCDC-220072 contains the supplementary crystallographic data for this paper. These data can be obtained free of charge via www.ccdc.cam. ac.uk/conts/retrieving.html (or form the Cambridge Crystallographic Data Centre, 12 Union Road, Cambridge CB2 1EZ, UK; fax: (+44)1223-336-033; or e-mail: deposit@ccdc.cam.ac.uk).

Molecular mechanics calculations: Initial structures, created by manual modification of X-ray crystal structures of $\beta$-cyclodextrin and 5,5'-dialdehydodithienylethene, as well as visualizations were carried out with the Quanta 97 software. ${ }^{[31]}$ Parameters were taken from Quanta 97 and point charges were assigned with the charge-template option. Residual charge was smoothed on carbon and nonpolar hydrogen atoms to provide overall neutral residues. A distance-dependent relative permittivity was applied, with $\varepsilon=1$. No cut-offs were used on the nonbonded interactions. Energy minimizations of the structures were performed in a solvent box of water molecules by using the steepest descent and adopted basis set Newton-Raphson methods until the root mean square of the energy gradient was less than $0.001 \mathrm{kcal} \mathrm{mol}^{-1} \AA^{-1}$.

\section{Acknowledgement}

This work was financially supported by the Council for the Chemical Sciences of the Netherlands Organization for Scientific Research (CWNWO; A.M.: CW-programmasubsidie 700.98.305; A.L.S.). We are grateful to J. J. D. de Jong and L. N. Lucas (University of Groningen, The Netherlands) for stimulating discussions and their help with the real-time UV/Vis measurements. We thank Dr. P. Berthault and Dr. N. Birlirakis (CEA Saclay, France) for performing high-resolution NMR experiments on dimer $\mathbf{4}$ and its TSPP complex.

[1] J. H. Hartley, T. D. James, C. J. Ward, J. Chem. Soc. Perkin Trans. 1 2000, 3155 .

[2] a) S. Shinkai, O. Manabe, Top. Curr. Chem. 1984, 121, 67; For a more recent review, see: b) M. V. Alfimov, O. A. Fedorova, S. P. Gromov, J. Photochem. Photobiol. A 2003, 158, 183.

[3] a) A. Ueno, H. Yoshimaru, R. Saka, T. Osa, J. Am. Chem. Soc. 1979, 101, 2779; b) A. Ueno, Y. Tomita, T. Osa, Tetrahedron Lett. 1983, 24, 5245; c) A. Ueno, M. Fukushima, T. Osa, J. Chem. Soc. Perkin Trans. 2 1990, 1067; d) M. Fukushima, T. Osa, A. Ueno, Chem. Lett. 1991, 709; e) F. Hamada, M. Fukushima, T. Osa, M. Ikeda, F. Toda, A. Ueno, Macromol. Chem. Rapid Commun. 1993, 14, 287.

[4] J. Szejtli, Chem. Rev. 1998, 98, 1743.

[5] T. Aoyagi, A. Ueno, M. Fukushima, T. Osa, Macromol. Rapid Commun. 1998, 19, 103.

[6] Y. Liu, C. T. Wu, G. P. Xue, J. Li, J. Inclusion Phenom. Macrocyclic. Chem. 2000, 36, 95.

[7] a) Y. Liu, C.-C. You, T. Wada, Y. Inoue, Tetrahedron Lett. 2000, 41, 6869 ; b) Y. Liu, Y. Chen, H. Y. Zhang, S.-X. Liu, X.-D. Guan, J. Org. Chem. 2001, 66, 8518; c) Y. Liu, C.-C. You, B. Li, Chem. Eur. J. 2001, 7, 1281; d) Y. Liu, L. Li, H.-Y. Zhang, Y. Song, J. Org. Chem. 2003, 68, 527 .
[8] a) A. Ruebner, Z. Yang, D. Leung, R. Breslow, Proc. Natl. Acad. Sci. USA 1999, 96, 14692; b) S. D. P. Baugh, Z. Yang, D. K. Leung, D. M. Wilson, R. Breslow, J. Am. Chem. Soc. 2001, 123, 12488.

[9] M. Irie, Chem. Rev. 2000, 100, 1685.

[10] B. L. Feringa, Molecular Switches, Wiley-VCH, Weinheim, 2001.

[11] M. Takeshita, K. Uchida, M. Irie, Chem. Commun. 1996, 1807.

[12] a) M. Takeshita, M. Irie, Tetrahedron Lett. 1998, 39, 613; b) M. Takeshita, M. Irie, J. Org. Chem. 1998, 63, 6643; c) M. Takeshita, C. F. Soong, M. Irie, Tetrahedron Lett. 1998, 39, 7717; d) S. H. Kawai, Tetrahedron Lett. 1998, 39, 4445.

[13] M. Irie, O. Miyataka, K. Uchida, T. Eruguchi, J. Am. Chem. Soc. 1994, 116, 9894.

[14] Preliminary results obtained with dimer 4 have been reported in: A. Mulder, A. Jukovic, L. N. Lucas, J. van Esch, B. L. Feringa, J. Huskens, D. N. Reinhoudt, Chem. Commun. 2002, 2734.

[15] L. N. Lucas, J. J. D. de Jong, J. H. van Esch, R. M. Kellogg, B. L. Feringa, Eur. J. Org. Chem. 2003, 155.

[16] E. van Dienst, B. H. M. Snellink, I. von Piekartz, M. H. B. Grote Gansey, F. Venema, M. C. Feiters, R. J. M. Nolte, J. F. J. Engbersen, D. N. Reinhoudt, J. Org. Chem. 1995, 60, 6537.

[17] D.-Q. Yuan, K. Ohta, K. Fujita, Chem. Commun. 1996, 821.

[18] J. F. Stoddart, Stereochemistry of Carbohydrates, Wiley Interscience, London, 1971, pp. 87-89.

[19] F. Venema, H. F. M. Nelissen, P. Berthault, N. Birlirakis, A. E. Rowan, M. C. N. Feiters, R. J. M. Nolte, Chem. Eur. J. 1998, 4, 2237.

[20] M. J. Pregel, E. Buncel, Can. J. Chem. 1991, 69, 130.

[21] H. F. M. Nelissen, M. C. Feiters, R. J. M. Nolte, J. Org. Chem. 2002, 67, 5901.

[22] Typical data obtained with a 5-mm aqueous solution of dimer 4 in an NMR tube irradiated at $313 \mathrm{~nm}$ for $2.5 \mathrm{~h}:{ }^{1} \mathrm{H}$ NMR spectroscopy: $34 \%$ open form and $66 \%$ closed form; UV/Vis spectroscopy and modeling: $33 \%$ open form, $67 \%$ closed form.

[23] a) K. Kano, R. Nishiyabu, T. Asada, Y. Kuroda, J. Am. Chem. Soc. 2002, 124, 9937; b) X.-P. Wang, J.-H. Pan, S.-M. Shuang, Spectrochim. Acta A 2001, 57, 2755; c) J. M. Ribo, J.-A. Farrera, M. L. Valero, A. Virgili, Tetrahedron 1995, 51, 3705.

[24] a) J. J. Michels, R. Fiammengo, P. Timmerman, J. Huskens, D. N. Reinhoudt, J. Inclusion Phenom. Macrocyclic. Chem. 2001, 41, 163; b) F. Venema, A. E. Rowan, R. J. M. Nolte, J. Am. Chem. Soc. 1996, $118,257$.

[25] J. S. Manka, D. S. Lawrence, J. Am. Chem. Soc. 1990, 112, 2440.

[26] M. V. Rekharsky, Y. Inoue, Chem. Rev. 1998, 98, 1875.

[27] a) E. D. Sternberg, D. Dolphin, C. Bruckner, Tetrahedron 1998, 54, 4151; b) C. E. Stilts, M. I. Nelen, D. G. Hilmey, S. R. Davies, S. O. Gollnick, A. R. Oseroff, S. L. Gibson, R. Hilf, M. R. Detty, J. Med. Chem. 2000, 43, 2403; c) W. B. Edwards, D. E. Reichert, D. A. d'Avignon, M. J. Welch, Chem. Commun. 2001, 1312; d) J. G. Moser, I. Rose, B. Wagner, T. Wieneke, A. Vervoorts, J. Inclusion Phenom. Macrocyclic. Chem. 2001, 39, 13.

[28] D. D. Perrin, W. F. L. Armarego, Purification of Laboratory Chemicals, 3rd ed., Pergamon, Oxford, 1989.

[29] G. M. Sheldrick, SHELSX86 program for crystal structure determination, University of Göttingen, Germany, $\mathbf{1 9 8 6}$.

[30] G. M. Sheldrick, SHELSX-97 program for crystal structure refinement, University of Göttingen, Germany, 1997.

[31] Quanta 97, Molecular Simulations, Waltham, USA.

Received: September 24, 2003 [F 5567] 